\title{
MATURATION, TRANSPLANTATION AND FERTILIZATION OF OVARIAN OOCYTES IN CATTLE
}

\author{
R. H. F. HUNTER,* R. A. S. LAWSON $\dagger$ AND L. E. A. ROWSON \\ A.R.C. Unit of Reproductive Physiology and Biochemistry, \\ University of Cambridge
}

(Received 10th February 1972, accepted 24th February 1972)

Cytological examination of the oocytes of a number of mammalian species has indicated that they will resume meiosis upon liberation from the Graafian follicle into a simple culture medium (Chang, 1955; Edwards, 1962, 1965a, b). Evaluation of the physiological status of such oocytes after periods of maturation would best be tested by noting their ability to undergo fertilization, cleavage and, ultimately, to produce viable young. Recent experiments have attempted in-vitro fertilization of mammalian eggs matured in culture and, whilst this has apparently yielded some success with human material (Edwards, Bavister \& Steptoe, 1969) and in the rabbit (Thibault \& Gérard, 1970), the contrary has proved the case in the large domestic species. In many experiments involving cow and pig eggs, sperm penetration of the zona pellucida of artificially matured oocytes was never obtained in vitro, but spontaneous formation of two female pronuclei was a common occurrence (Foote \& Thibault, 1969; C. Thibault, M. Gérard \& R. H. F. Hunter, unpublished). In the present study, the incidence and degree of maturation of ovarian oocytes has been examined in a simple culture system, after which the fertilizability of these oocytes was noted following their transplantation to the oviducts of inseminated cows.

Oocytes were taken from the ovaries of slaughtered cows, these being returned to the laboratory in a warm vacuum flask within $20 \mathrm{~min}$ of slaughter. In three instances, ovarian tissue was also obtained by surgical intervention. Oocytes and follicular fluid were aspirated from Graafian follicles 2 to $6 \mathrm{~mm}$ in diameter and, in the maturation experiments, the follicular contents were added to Falcon dishes containing equilibrated paraffin oil and Tyrode's solution at $37^{\circ} \mathrm{C}$. Using a dissecting microscope, oocytes encompassed within a dense cumulus cell mass were selected for culture in microdrops of medium under oil in separate Falcon dishes. The culture medium ( $\mathrm{pH} 7.4$ to 7.6 ) consisted of approximately a 50:50 mixture of Tyrode's solution and homologous follicular fluid collected from fresh ovarian tissue. The Tyrode's solution had been modified by the addition of $1 \mathrm{~g}$ bovine serum albumin (Sigma) together with 100,000 units penicillin and $50 \mathrm{mg}$ streptomycin/litre. The cultures were maintained at $37^{\circ} \mathrm{C}$ in a humidified atmosphere of $95 \%$ air $/ 5 \% \mathrm{CO}_{2}$. At the end of selected periods, oocytes were freed of cumulus cells by dissection or

\footnotetext{
* Present address: School of Agriculture, University of Edinburgh, West Mains Road, Edinburgh 9. † Present address: S.S. Cameron Laboratories, State Research Farm, Werribee 3030, Victoria, Australia.
} 
TABLE 1

MATURATION OF BOVINE OVARIAN OOCYTES WHEN GULTURED IN A MODIFIED TYRODE'S SOLUTION CONTAINING HOMOLOGOUS FOLLIGULAR FLUID

\begin{tabular}{|c|c|c|c|c|c|c|}
\hline \multirow{2}{*}{$\begin{array}{c}\text { Period } \\
\text { of culture }\end{array}$} & \multirow{2}{*}{$\begin{array}{c}\text { No. of } \\
\text { oocytes } \\
\text { examined }\end{array}$} & \multicolumn{5}{|c|}{ No. of oocytes maturing to:* } \\
\hline & & G.V. & P.M. & $M_{1}$ & $A_{1}$ & Degenerating \\
\hline $\begin{array}{l}25 \mathrm{hr} \\
28 \mathrm{hr} 25 \mathrm{~min} \\
28 \mathrm{hr} 25 \mathrm{~min} \\
29 \mathrm{hr} 10 \mathrm{~min} \\
36 \mathrm{hr} \\
44 \mathrm{hr}\end{array}$ & $\begin{array}{r}9 \\
3 \\
6 \\
14 \\
11 \\
10\end{array}$ & $\begin{array}{l}= \\
= \\
z\end{array}$ & $\begin{array}{l}\frac{1}{2} \\
= \\
=\end{array}$ & $\begin{array}{r}8 \\
1 \\
6 \\
14 \\
10 \\
7\end{array}$ & $\begin{array}{l}- \\
\frac{-}{2}\end{array}$ & $\begin{array}{l}\overline{-} \\
\frac{-}{1} \\
1\end{array}$ \\
\hline Total & 53 & - & 3 & 46 & 2 & 2 \\
\hline
\end{tabular}

* Stages of the first meiotic division: G.V., germinal vesicle; P.M., prometaphase; $M_{1}$, first metaphase; $A_{1}$, first anaphase.

treatment with hyaluronidase, and prepared as whole mounts (Chang, 1952). They were fixed in $25 \%$ acetic alcohol, stained with $0.5 \%$ aceto-orcein and examined by phase-contrast microscopy.

In a preliminary study, ninety-eight oocytes were fixed shortly after recovery from the ovaries of eleven animals. Ninety-two of these oocytes $(93.9 \%)$ possessed an intact germinal vesicle situated peripherally in the vitellus and containing various arrangements of nucleoli and threads or lumps of chromatin. In the remaining six oocytes, the nuclear membrane and nucleoli were no longer visible and the chromatin was condensed into a compact lump or as distinct chromosomes. One of these oocytes had a degenerating first polar body, and the ooplasm was also atretic.

Having established the proportion of follicular oocytes that might be expected to possess a nucleus at the diplotene or dictyotene stage (see Baker \& Franchi, 1967), fifty-three oocytes from the ovaries of five animals were cultured for periods of 25 to $44 \mathrm{hr}$ (Table 1). A high proportion $(86.8 \%$ ) of the selected oocytes matured as far as metaphase of the first meiotic division (Pl. 1, Fig. 1). Two oocytes were in first anaphase after $44 \mathrm{hr}$ of culture, and two

\section{EXPLANATION OF PLATE 1}

Phase-contrast photomicrographs of bovine oocytes which were fixed after periods of culture ranging from 25 to $44 \mathrm{hr}$ (Figs 1 to 4). The oocytes in Figs 5 to 7 had been cultured for approximately $25 \mathrm{hr}$ and were then transplanted to the oviducts of inseminated oestrous cows.

FIG. 1. A tightly condensed arrangement of chromosomes in metaphase of the first meiotic division after $25 \mathrm{hr}$ of culture. $\times 1200$.

Figs 2 and 3. Polar and equatorial views of the chromosomes in the first meiotic metaphase showing the material associated with the metaphase spindle after $29 \mathrm{hr}$ of culture. $\times 1200$.

Fig. 4. Commencement of dispersal of the chromosomes from a metaphase arrangement on the first meiotic spindle after $44 \mathrm{hr}$ of culture. $\times 800$.

Fic. 5. The fertilizing spermatozoon in an oocyte recovered $22 \mathrm{hr}$ after transplantation. Note the decondensation of material at the anterior end of the sperm head and the beginning of nuclear swelling. The mid-piece is already detached. $\times 1200$.

Fias 6 and 7 . Fertilized pronuclear eggs recovered from the oviducts $21 \mathrm{hr}$ after transplantation. The mid-piece and a portion of the fertilizing sperm tail adjoin the male pronucleus in each egg. Note the second polar body in Fig. $6(\times 400)$, and the split at the rostral end of the mid-piece in Fig. $7(\times 800)$. 
PLATL I
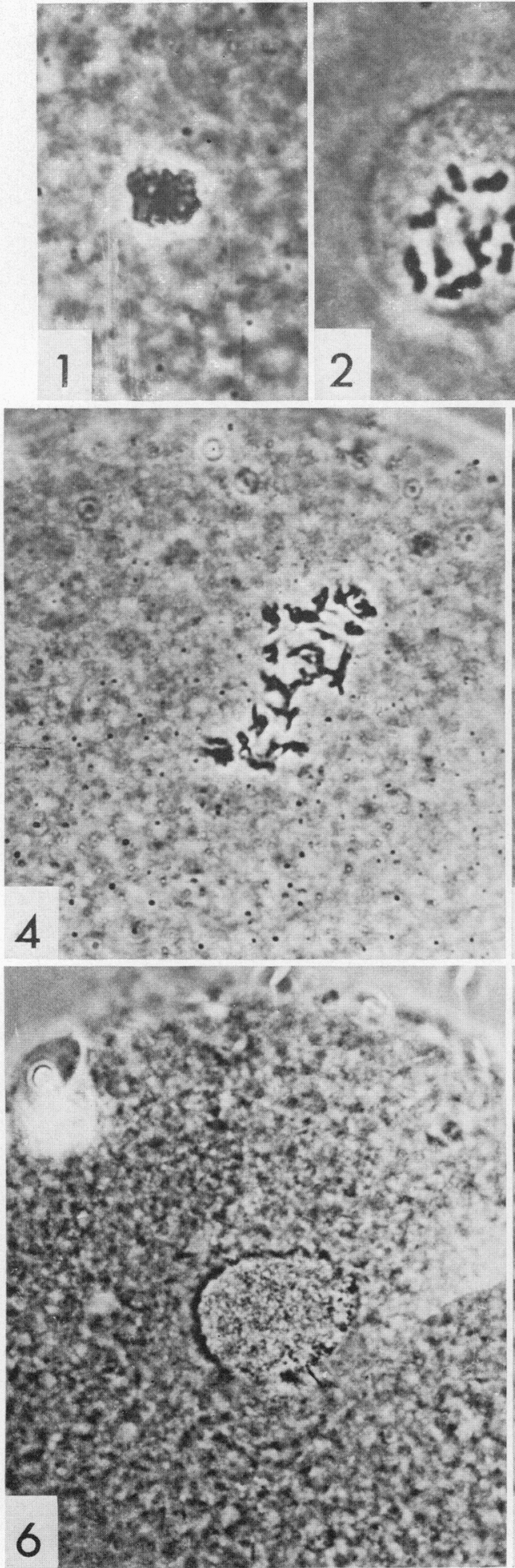
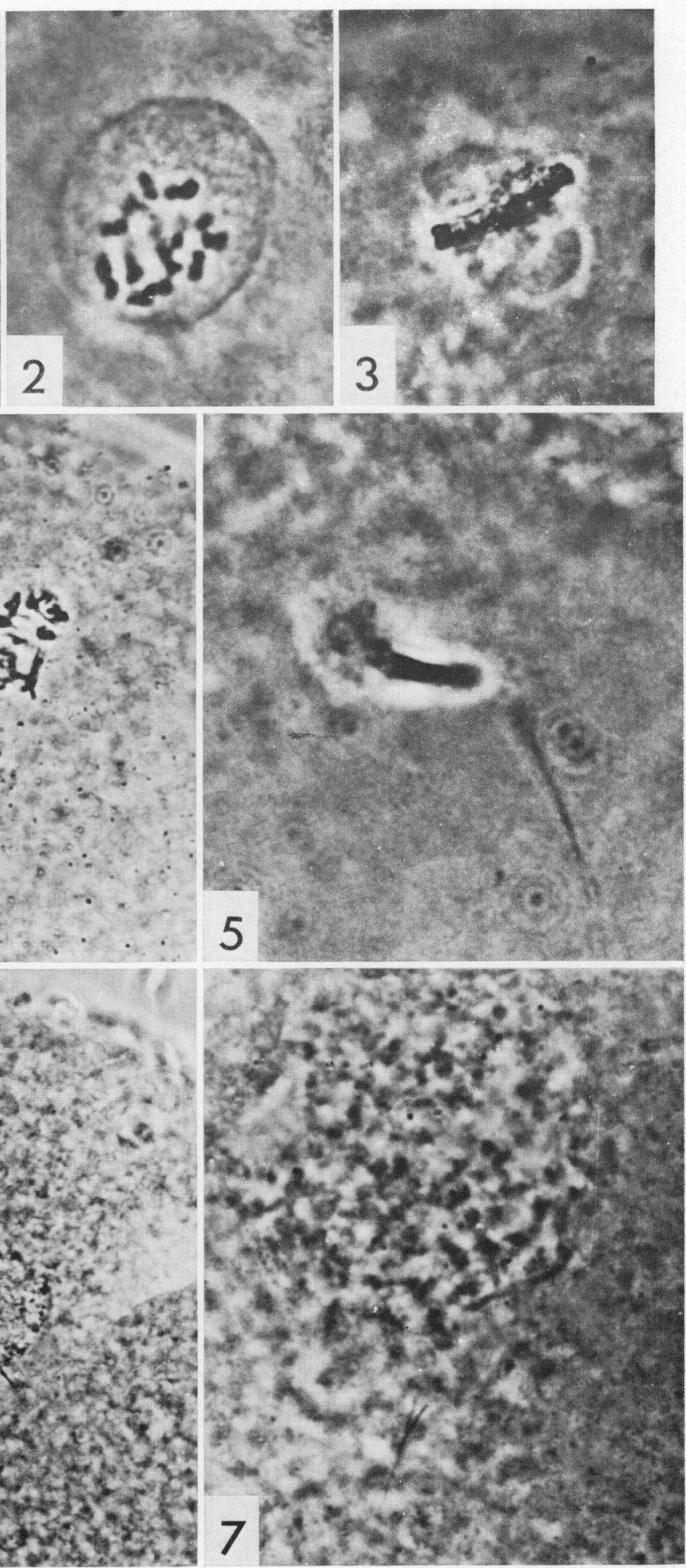
other oocytes showed evidence of degeneration. Various forms of condensed or membranous material were seen in association with the spindle apparatus in oocytes cultured for between 25 and $36 \mathrm{hr}$ (Pl. 1, Figs 2 and 3). By contrast, this abnormality was not found in the ten oocytes examined $44 \mathrm{hr}$ after liberation from the follicles. However, breakdown of the metaphase arrangement had commenced, and some dispersion of the chromosomes was apparent (Pl. 1, Fig. 4).

The culture system was considered inadequate to support maturation beyond first metaphase. Rather than attempting to develop a more appropriate medium, oocytes presumed to have reached first meiotic metaphase in culture were transplanted to the oviducts of oestrous heifers. It was reasoned that the tubal fluid of animals at this stage might prove suitable for completion of oocyte maturation. Oestrus was detected by penning females with a vasectomized bull shortly

TABLE 2

RESULTS FOLLOWING TRANSPLANTATION OF PARTIALLY MATURED OVARIAN OOCYTES TO THE OVIDUCTS OF INSEMINATED OESTROUS cows

\begin{tabular}{l|c|c|c|c}
\hline & Exp. 1 & Exp. 2 & Exp. 3 & $\begin{array}{c}\text { Total no. } \\
\text { of eggs }\end{array}$ \\
\hline No. of eggs transplanted & 21 & 16 & 18 & 55 \\
No. of eggs recovered & 4 & 14 & 11 & 29 \\
No. of eggs with spermatozoa & 3 & $5 *$ & 9 & 17 \\
Mean no. of spermatozoa/egg & 5 & $20 \cdot 8$ & $4 \cdot 6$ & $\frac{1}{16}$ \\
No. of penetrated and activated eggs & 3 & 4 & 9 & 11 \\
No. of pronuclear eggs & 2 & 3 & 6 & 11 \\
\hline
\end{tabular}

* Spermatozoa were not associated with the eight eggs recovered from one oviduct.

before the operation. The fertilizability of the oocytes was judged after instilling $1 \mathrm{ml}$ freshly collected semen directly into each uterine horn immediately before egg transfer. Both manipulations were achieved by means of a midventral laparotomy, oocytes being deposited with a minimum of culture medium into the tubal ampulla.

Fifty-five oocytes that had been cultured for periods of $24 \mathrm{hr} 10 \mathrm{~min}$ to $25 \mathrm{hr} 55 \mathrm{~min}$ were transplanted to six oviducts in three experiments (Table 2). The recipients were slaughtered $21 \mathrm{hr}$ to $22 \mathrm{hr} 50 \mathrm{~min}$ after the operation, at which time each had a single, recent ovulation point. Twenty-nine tubal eggs and one ruptured zona pellucida were recovered; twenty-eight of the twentynine eggs were completely denuded of cumulus and corona cells. Sixteen of these eggs had been penetrated by a spermatozoon and showed various stages of the fertilization process. However, two of these penetrated eggs from two animals undoubtedly represented native eggs, being flushed from tubes adjoining the ovary with the recent ovulation. None of eight eggs recovered from the corresponding tube in the third heifer was penetrated or had spermatozoa attached, but one presented the appearance of a two-cell egg. Fourteen of the eggs classified as fertilized must have represented cultured and transplanted oocytes.

Certain aspects of the fertilization of cow eggs, as seen in this series of sixteen penetrated eggs, deserve special mention. Eleven of the eggs were at the pro- 
nuclear stage and in each of these, the sperm mid-piece and a portion of the tail were detected in the vitellus (PI. 1, Figs 6 and 7). In six of these eleven eggs, the apposing pronuclei were located eccentrically. A difference in the size of the pronuclei was also noted in four eggs, the male structure being slightly larger in each case. Three eggs showed evidence of recent penetration, and had chromosomes arranged in anaphase of the second meiotic division. The sperm head was swollen, and exhibited a decondensation of nuclear material at the anterior end of the head (Pl. 1, Fig. 5). Two two-cell eggs were also recovered in this series and both had an intact nucleus in each blastomere. One of these eggs probably arose from the native ovulation. First and second polar bodies were located on only four of the pronuclear eggs but the second polar body, containing a compact lump of chromatin, was still visible on eleven eggs.

As the moment of sperm penetration and activation of these eggs was unknown, the rate of their development cannot be compared with that of other species. But the finding of two two-cell eggs $22 \mathrm{hr} 50 \mathrm{~min}$ after transplantation may indicate that cleavage occurred about $16 \mathrm{hr}$ after sperm penetration, assuming that 6 to $8 \mathrm{hr}$ were required for completion of oocyte maturation. The latter estimate would more than cover the time required for sperm capacitation and passage of the spermatozoa to the site of fertilization.

The results of this study are encouraging, and suggest that when the technique of oocyte culture is perfected, large numbers of cow eggs may be harvested from appropriate follicles, cultured, and then fertilized in recipient animals or possibly in vitro. However, before attempting to obtain complete maturation and fertilization of selected oocytes in vitro, it is important to test the viability of the eggs fertilized in recipient cows. If normal offspring develop from these embryos, then a method of reducing germ cell wastage and of propagating suitable genetic material will be available.

R.H.F.H. acknowledges the award of a Senior Research Fellowship by the Milk Marketing Board, and also wishes to thank Dr C. Polge for the provision of facilities in his laboratory.

We are grateful to Dr A. Brand, Dr R. Moor and Dr R. Tervit for assistance during the operations, and to the staff of the Animal Research Station for supervision of the animals. Mr R. J. Patman kindly printed the photographs.

\section{REFERENCES}

BAKER, T. G. \& FraNchr, L. L. (1967) The fine structure of chromosomes in bovine primordial oocytes. 7. Reprod. Fert. 14, 511.

Ghang, M. C. (1952) Fertilizability of rabbit ova and the effects of temperature in vitro on their subsequent fertilization and activation in vivo. $\mathcal{F}$. exp. Zool. 121, 351.

Ghang, M. G. (1955) The maturation of rabbit oocytes in culture and their maturation, activation, fertilization and subsequent development in the Fallopian tubes. F. exp. Zool. 128, 379.

EDWARDs, R. G. (1962) Meiosis in ovarian oocytes of adult mammals. Nature, Lond. 196, 446.

EDwards, R. G. (1965a) Maturation in vitro of mouse, sheep, cow, pig, rhesus monkey and human ovarian oocytes. Nature, Lond. 208, 349.

EDWARDs, R. G. (1965b) Maturation in vitro of human ovarian oocytes. Lancet, ii, 926.

Edwards, R. G., Bavister, B. D. \& Steptoe, P. G. (1969) Early stages of fertilization in vitro of human oocytes matured in vitro. Nature, Lond. 221, 632.

Foote, W. D. \& Thibault, C. (1969) Recherches expérimentales sur la maturation in vitro des ovocytes de truie et de veau. Annls Biol. anim. Biochim. Biophys. 9, 329.

Thibault, C. \& Gérard, M. (1970) Facteur cytoplasmique nécessaire à la formation du pronucleus mâle dans l'ovocyte de lapine. C. r. hebd. Séanc. Acad. Sci., Paris, 270, 2025. 